\title{
Come for a Job, Stay for the Socializing: Gratifications Received from LinkedIn Usage
}

\author{
Steven W Brewer \\ College of Saint Mary, Omaha, Nebraska, USA \\ (iD) 0000-0003-1030-5847 \\ ⿶sbrewer@csm.edu
}

ARTICLE INFO

Received: 24 September 2018

Accepted: 31 October 2018

Published: 12 November 2018

DOI: https://doi.org/10.12973/ojcmt/3956

ABSTRACT

LinkedIn is the leading social network site focusing on professional life, with over 500 million customers, but has received far less research attention than Facebook and other personal networks. This study is one of the first to examine gratifications received from using LinkedIn by U.S. adults and relationships between those gratifications and how the site is utilized. Uses and Gratifications Theory served as conceptual framework. The cross-sectional study surveyed 390 active LinkedIn customers 25 and older about gratifications received, intensity of attitudes, and site usage. Exploratory factor analysis and structural equation modeling were used to identify three gratification factors for using LinkedIn: jobs and job affairs, social aspects of employment, and finding old and new friends easily. The social aspects of employment factor had a significant relationship with both intensity of attitudes toward LinkedIn and site usage. This was a surprising finding, since LinkedIn is commonly associated only with utilitarian career-oriented motives, rather than hedonic gratifications like socializing.

Keywords: LinkedIn, social network sites, gratifications from social networks, uses and gratifications theory, why people use LinkedIn, differences between LinkedIn and Facebook

\section{INTRODUCTION}

Social network sites began as cooperative platforms for staying in touch with friends, and have evolved into global, profit-oriented enterprises. Their growth and near-ubiquity in modern life make these social network sites (SNSs) a consequential topic for site users, managers, and scholarly researchers.

The majority of SNS research has examined Facebook, which focuses on personal life, with numerous studies in multiple nations analyzing customer gratifications received from using the site (Kim, Shin, \& Ahn, 2011; Park \& Lee, 2014; Urista, Dong, \& Day, 2008). There has been relatively little examination of gratifications from using LinkedIn, which is the leading SNS focused on professional life and has over 500 million customers worldwide ("Most famous social network sites," 2018). This study is one of the first to investigate gratifications received from using LinkedIn.

\section{Purpose of the Study}

The purpose of this study was to understand the gratifications provided by LinkedIn to active customers in the U.S. who are 25 and older, and whether those gratifications 
were related to intensity of attitudes and to site usage. The research can assist marketing and recruiting managers in considering the site's strategic use, and can increase scholarly understanding of the professional use of SNSs.

After examining literature on five of the largest SNSs, Blank and Lutz (2017, pp. 13) concluded that surprisingly few studies have focused on LinkedIn, and stated that it deserves more scrutiny. Because the site focuses on professional life, gratifications from its use likely diverge from those found in earlier Facebook studies, but potential similarities and differences are not currently clear because of a lack of research. It is also uncertain at present how various gratifying factors are related to the ways in which the site is used and attitudes regarding it. This study proposed to partially address the gap in the research.

\section{LITERATURE REVIEW}

\section{Uses and Gratifications Theory}

Uses and Gratifications Theory (UGT) served as conceptual framework; it is an audience-centered approach to understanding mass communication. Other media effect theories question what media do to people, but UGT focuses on what people do with media (Florenthal, 2015, pp. 19). Researchers utilizing this theory strive to understand the gratifications that people receive from media, and how those gratifications drive behavior. Studies are concerned with the social and psychological needs that generate expectations of the mass media or other sources. These lead to differential patterns of media exposure, resulting in need gratification and other consequences, perhaps mostly unintentional (Katz \& Blumler, 1974).

Audience gratifications can be derived from at least three sources: content of the media, exposure to the media per se, and social context that typifies the exposure to media (Katz \& Blumler, 1974). This last source is particularly relevant to SNSs, which rely on customers consuming content created by fellow users and creating their own content.

\section{Research on Social Network Sites}

Studies on Other Aspects of LinkedIn. A number of studies have been conducted about various aspects of LinkedIn other than gratifications from its use. These include importance of profile photos (Edwards, Stoll, Faculak, \& Karman, 2015), examinations of site geography (Papacharissi, 2009), use by salespeople (Inks, Schetzsle, \& Ovila, 2012; Schultz, Schwepker, \& Good, 2012), use by large and small organizations (Witzig, Spencer, \& Galvin, 2012), use in job seeking (DeKay, 2009), relationship between gender and site usage (Peachy, 2013; Zide, Elman, \& Shohani-Denning, 2014), and income levels of site users (Blank \& Lutz, 2016).

Studies of Facebook Gratification. Dozens of studies have examined gratifications from using Facebook, which is the largest ("Most famous social network sites," 2018) and most-studied SNS (Zhang and Leung, 2015). This research has been conducted in the U.S. (Bonds-Raacke \& Raacke, 2010; Papacharissi \& Mendelson, 2011), in multiple Asian countries (Cheung, Chiu, \& Lee, 2011; Alhabash, Park, Kononova, et al., 2012), and elsewhere around the world (Dhaha \& Igale, 2013; Fortier \& Burkell, 2016). Some common Facebook gratifications emerge from an examination of these studies; these include keeping in touch, feeling connected to others, entertainment, passing time, following group norms, and social surveillance. 
Studies of LinkedIn Gratifications

A handful of studies on gratifications from using LinkedIn have been published. Basak and Calisir (2014, pp. 4) conducted quantitative exploratory research with college students in Turkey, finding seven gratifications Their published LinkedIn gratifications scale was used as part of the research instrument in this study. After conducting qualitative interviews with U.S. college students, Florenthal (2015, pp. 25) proposed four gratification categories. Shyron (2015, pp. 16) surveyed LinkedIn adult users in China to find that they were motivated by four factors. Vivekananthamoorthy, Naganathan, and Rajkumar (2016, pp. 8) studied the reasons that Indian college students engaged in electronic word-of-mouth behavior via LinkedIn and identified three gratification factors. The LinkedIn gratifications found in these earlier studies are depicted in Table 1.

Table 1. Gratification Factors from Using LinkedIn Found in Four Studies

\begin{tabular}{|c|c|c|}
\hline Author(s) & LinkedIn Gratifications Found & Description \\
\hline \multirow[t]{7}{*}{ Basak and Calisir, 2014} & Self-Promotion & $\begin{array}{l}\text { Introducing oneself to others through } \\
\text { communication }\end{array}$ \\
\hline & Group Activities & Engaging in LinkedIn groups \\
\hline & Jobs and Job Affairs & $\begin{array}{l}\text { Searching for jobs and obtaining information } \\
\text { about professional world }\end{array}$ \\
\hline & $\begin{array}{l}\text { Finding Old and New Friends } \\
\text { Easily }\end{array}$ & Locating connections with ease \\
\hline & Follow Up & $\begin{array}{l}\text { Following career progression of connections, } \\
\text { access employment information }\end{array}$ \\
\hline & Profile Viewer Data & Seeing who has viewed your profile \\
\hline & Professional Networking & Building a network, making new connections \\
\hline \multirow[t]{4}{*}{ Florenthal, 2015} & Interpersonal communication & $\begin{array}{l}\text { Connecting with other professionals and with } \\
\text { businesses }\end{array}$ \\
\hline & Online identity & $\begin{array}{l}\text { Gaining visibility and be able to market } \\
\text { oneself }\end{array}$ \\
\hline & Information & $\begin{array}{l}\text { Reading articles and creating posts. Following } \\
\text { companies/organizations and checking others' } \\
\text { profiles. }\end{array}$ \\
\hline & Career advancement & $\begin{array}{l}\text { Using for recruiting and posting jobs, access } \\
\text { to jobs and internships }\end{array}$ \\
\hline \multirow[t]{4}{*}{ Shyron, 2015} & Gathering job-related information & $\begin{array}{l}\text { Collecting information about industry and } \\
\text { new events relating to company or } \\
\text { competitors }\end{array}$ \\
\hline & Feeling of belongingness & $\begin{array}{l}\text { Being accepted by and feeling belonging to } \\
\text { industry }\end{array}$ \\
\hline & $\begin{array}{l}\text { Developing and enlarging } \\
\text { professional network }\end{array}$ & $\begin{array}{l}\text { Creating professional network within } \\
\text { company }\end{array}$ \\
\hline & Expanding career & $\begin{array}{l}\text { Promoting oneself, to look for collaborators } \\
\text { and to keep in touch with contacts outside } \\
\text { company }\end{array}$ \\
\hline \multirow[t]{3}{*}{$\begin{array}{l}\text { Vivekananthamoorthy, } \\
\text { Naganathan, and } \\
\text { Rajkumar., } 2015\end{array}$} & Expert opinion seeking & $\begin{array}{l}\text { Gaining information from professors and } \\
\text { other authorities on academic and } \\
\text { professional topics }\end{array}$ \\
\hline & $\begin{array}{l}\text { Notification of profile updates and } \\
\text { skill endorsements }\end{array}$ & $\begin{array}{l}\text { Following career progress and activities of } \\
\text { connections }\end{array}$ \\
\hline & $\begin{array}{l}\text { Networking with others and view } \\
\text { others' profiles }\end{array}$ & $\begin{array}{l}\text { Finding connections and staying in touch with } \\
\text { them }\end{array}$ \\
\hline
\end{tabular}


Comparing Gratifications from Personal and Professional SNSs

Gratifications found in these four LinkedIn studies show some similarities with those identified in Facebook research. Customers want to stay in touch with people they know offline, and they like to make new connections. They seek information, and they wish to present a certain image. The difference is that LinkedIn customers desire to learn about potential employers and jobs, are not seeking entertainment or to pass time, and are attempting to present a professional rather than a social image. However, it may be difficult to generalize these LinkedIn findings to working professionals because three of these studies examined college students, and other scholars have found that students primarily sign up for LinkedIn under pressure from others and use it infrequently (Ezumah, 2013, pp. 32; Florenthal, 2015, pp. 27).

\section{Site Usage Definitions}

The term "customer" is defined as an individual who has signed up for LinkedIn and created a profile that is available to other site users. The term "active customer" will denote LinkedIn customers who viewed their profile at least once in the last month. The term "friend" means essentially the same as "connection," but in personal SNSs such as Facebook. In this study, "connection" will refer to LinkedIn customers who are connected via the site, while "friend" will refer to connected Facebook customers.

\section{HYPOTHESES AND RESEARCH MODEL}

Based on a literature review, a gap in knowledge was identified and research questions, hypotheses, and a model were formulated. This study sought to answer the question, "Is there a relationship between gratifications from using LinkedIn received by active customers in the U.S. ages 25 and older and the intensity of LinkedIn attitudes and site usage of those customers?"

To determine specific hypotheses and a model, a gratification scale developed by Basak and Calisir (2014) was used to investigate the gratifications received from active U.S. LinkedIn customers 25 and older. Exploratory factor analysis of responses from the sample members discussed in the Methodology section revealed three gratifications from using LinkedIn, which served as exogenous variables in the study:

- Jobs and Job Affairs - LinkedIn customers obtain information about the professional world and search for jobs, and are able to track these topics through the site,

- Social Aspects of Employment - LinkedIn customers are gratified by the social aspects of employment. They are sensitive to their online presence, they want to see how others are portraying themselves, and they are curious about how they may appear, and

- Finding Old and New Friends Easily - LinkedIn customers find connections in the site based on suggestions of people they know, by using the search feature, and by visiting alumni pages associated with an employer or college.

The intensity of LinkedIn attitudes and LinkedIn usage served as the two endogenous variables. Intensity of LinkedIn attitudes was a measure of attitudes regarding the site and feelings of connection to the community of users. LinkedIn usage was a measure of frequency of site visits, length of membership, and average length of time per site visit. Figure 1 depicts the resulting research model. 


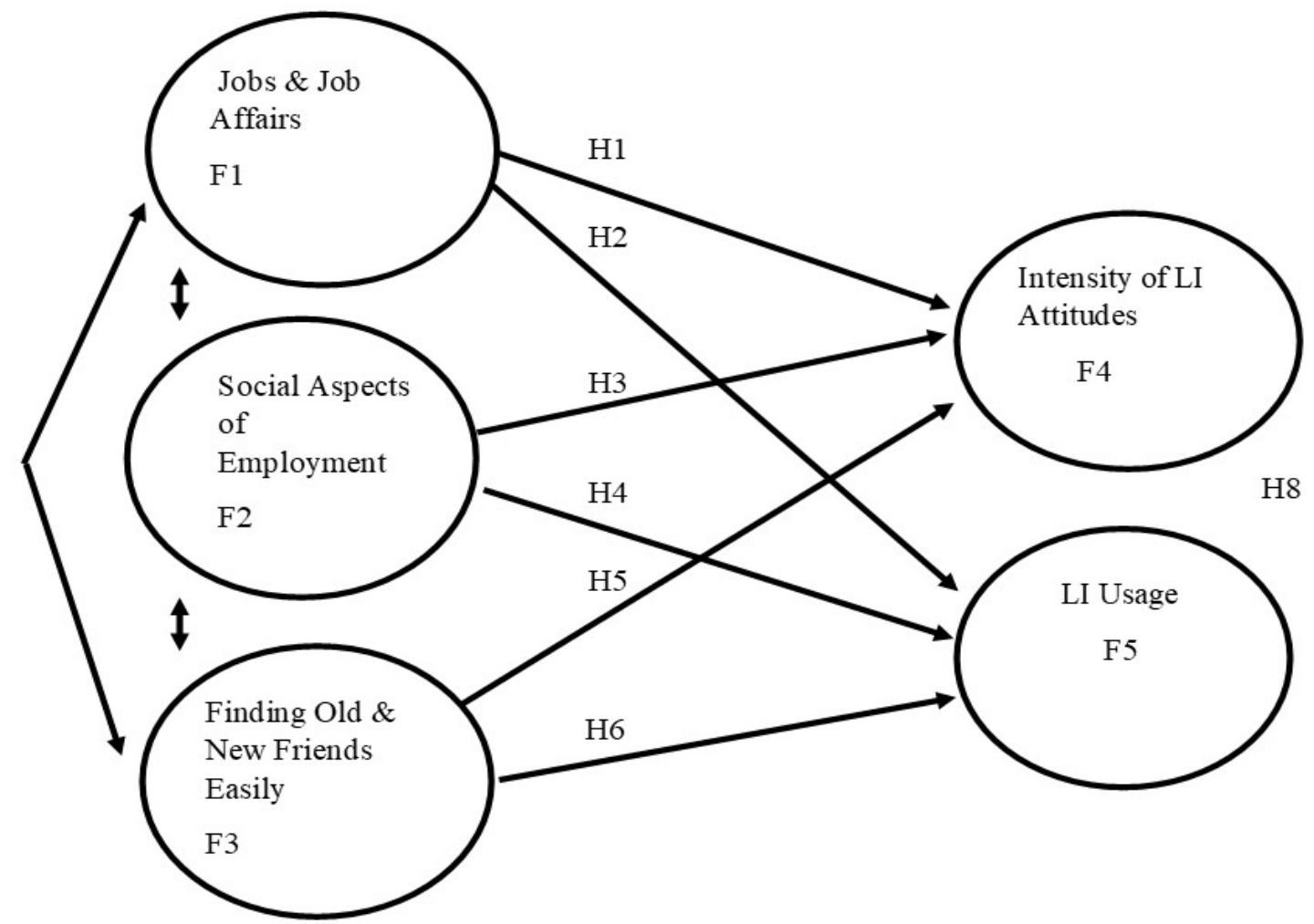

Figure 1. Research Model

\section{Hypotheses}

$\mathbf{H}_{1}-$ Hypothesis 1 was that a relationship exists between the LinkedIn gratification of learning about Jobs and Job Affairs and intensity of attitudes toward LinkedIn, with relationship going from gratification to attitudes.

$\mathbf{H}_{2}$ - Hypothesis 2 was that a relationship exists between the LinkedIn gratification of learning about Jobs and Job Affairs and usage of the LinkedIn site, with relationship going from gratification to usage.

$\mathbf{H}_{3}$ - Hypothesis 3 was that a relationship exists between the LinkedIn gratification of the Social Aspects of Employment and intensity of attitudes toward LinkedIn, with relationship going from gratification to attitudes.

$\mathbf{H}_{4}$ - Hypothesis 4 was that there is a relationship between the LinkedIn gratification of the Social Aspects of Employment and usage of the LinkedIn site, with relationship going from gratifications to usage.

$\mathbf{H}_{5}-$ Hypothesis 5 was that a relationship exists between the LinkedIn gratification of Finding Old and New Friends Easily and attitudes toward LinkedIn, with relationship going from gratification to attitudes.

$\mathbf{H}_{6}$ - Hypothesis 6 was that a relationship exists between the LinkedIn gratification of Finding Old and New Friends Easily and usage of the LinkedIn site, with relationship going from gratification to usage.

$\mathbf{H}_{7}-$ Hypothesis 7 was that the three gratifications from using LinkedIn are interrelated. These are not discrete benefits.

$\mathbf{H}_{8}-$ Hypothesis 8 was that there is no relationship between intensity of attitudes toward LinkedIn and usage of the LinkedIn site. 


\section{METHODOLOGY}

This study used a longitudinal survey of U.S. LinkedIn active customers 25 and older; this was appropriate because UGT assumes that media users are active, that mass media use is goal-directed, and that users are sufficiently self-aware to be able to report their motives and interests in using media (Katz \& Blumler, 1974). Anyone in the 18-24 age range was excluded from the study in order to focus on professional usage rather than on college students.

\section{Instrument Development}

LinkedIn Gratifications. The research instrument used two previously published scales. Gratifications from using LinkedIn were operationally defined by responses to Basak and Calisir's (2014, pp. 3) LinkedIn Gratifications Scale, which included 33 measures related to the significance of various site usage outcomes. This scale is depicted in Table 2.

Table 2. LinkedIn Gratification Scale (Basak \& Calisir, 2014)

\begin{tabular}{|c|c|}
\hline Item Number & Description of Item \\
\hline 1 & Building a network \\
\hline 2 & Seeing who's viewed my profile \\
\hline 3 & Searching for jobs \\
\hline 4 & Following the career progression of my contacts \\
\hline 5 & Getting information about professional world \\
\hline 6 & Being informed about current business affairs \\
\hline 7 & Viewing job ads posted by companies \\
\hline 8 & Skill endorsements \\
\hline 9 & Making new connections \\
\hline 10 & Joining and participating in groups \\
\hline 11 & Finding out job opportunities \\
\hline 12 & Online presence \\
\hline 13 & Marketing myself \\
\hline 14 & Getting into contact with others \\
\hline 15 & Accessing employment information \\
\hline 16 & Jobs you may be interested in \\
\hline 17 & Discussions in groups \\
\hline 18 & Viewing resume of others \\
\hline 19 & Using LinkedIn as a Curriculum Vitae \\
\hline 20 & Reaching out to recruiters, company executives etc. \\
\hline 21 & Making a direct contact with the business world \\
\hline 22 & Knowledge sharing \\
\hline 23 & Keeping in touch with my contacts \\
\hline 24 & Following companies \\
\hline 25 & Profile updates \\
\hline 26 & Meeting with like-minded professionals through groups \\
\hline 27 & User-friendly search engine \\
\hline 28 & Suggestion of people you may know \\
\hline 29 & Seeing the number of profile views \\
\hline 30 & Personal development opportunities \\
\hline 31 & Helpful in career planning \\
\hline 32 & Finding friends, alumni, etc. \\
\hline 33 & Ease of use \\
\hline
\end{tabular}

LinkedIn Intensity. Intensity of LinkedIn attitudes was measured using Ellison, Steinfeld, and Lampe's (2007, pp. 1150) Facebook Intensity Scale, modified for LinkedIn. This 6-item scale asks about attitudes regarding the site and feelings of connection to the community of users. The Facebook Intensity Scale has been used by several other researchers, including Steinfield, Ellison, and Lampe (2008, pp. 440) and Lampe, Wohn, Vitak, et al. (2011, pp. 334). There does not appear to be a published scale regarding 
LinkedIn intensity, so Ellison et al.'s scale (2007, pp. 1150) was adapted. It addresses aspects common to all SNSs and does not refer to any features unique to Facebook, so is modifiable simply by replacing the word "Facebook" with "LinkedIn." However, the modified scale was tested in person and online before final use.

Site Usage. Several measures regarding LinkedIn usage were incorporated. These asked about number of times viewing LinkedIn home page in the last month, length of LinkedIn membership, version of LinkedIn used (free or paid), number of LinkedIn connections, and average length of time per site visit. Few previous scholarly studies have asked specific questions about how LinkedIn was used, so these measures were adapted from annual surveys of LinkedIn customers conducted by Breitbarth (2015).

Demographics. The instrument also contained six measures on demographic factors. These asked about age range, gender, education, current employment status, employment intent in the next year, and household income.

Testing the Research Instrument. The research instrument was first tested in person with graduate college students 25 and older who were active LinkedIn customers. After modifications were made, the instrument was then tested online with 104 U.S. LinkedIn customers who met the same inclusion standards and were members of online panels administered by Qualtrics. Changes were made after these rounds of in-person and online testing, the final research instrument was prepared in Qualtrics online survey software, and a link was delivered to Qualtrics for distribution to members of its online panels. The company collected responses from 408 qualified respondents in November 2016. As the result of data screening procedures, the final sample was reduced to 390 respondents.

After responses were collected, exploratory factor analysis was performed on the 33 gratification measures using Principal Component Analysis, the same technique used by Basak and Calisir (2014), in order to identify gratification factors from using LinkedIn. Structural equation modeling (SEM) was then used to estimate goodness-of-fit for the measurement model of constructs regarding gratifications, intensity of attitudes, and site usage. Finally, the structural model was tested using SEM to evaluate significant relationships between the variables.

\section{Sample}

The sample was comprised of LinkedIn customers in the U.S. who were 25 or older and had viewed their LinkedIn profile page within the last 30 days. When the number of SNS users is reported, it is typically for active accounts, which means accounts that have been accessed in the past 30 days ("Global social networks by number," 2015). Descriptive statistics regarding sample members can be seen in Table 3. 


\begin{tabular}{|c|c|}
\hline Category & \% of Total \\
\hline \multicolumn{2}{|l|}{ Gender } \\
\hline Female & $58 \%$ \\
\hline Male & $42 \%$ \\
\hline Total & $100 \%$ \\
\hline \multicolumn{2}{|l|}{ Age Category } \\
\hline Under 25 & $0 \%$ \\
\hline $25-34$ & $49 \%$ \\
\hline $35-49$ & $38 \%$ \\
\hline $50-64$ & $12 \%$ \\
\hline 65 or older & $0.25 \%$ \\
\hline Total & $100 \%$ \\
\hline \multicolumn{2}{|l|}{ Highest Education Level Achieved } \\
\hline High school graduate or GED & $14 \%$ \\
\hline Some college & $30 \%$ \\
\hline Bachelor's degree & $33 \%$ \\
\hline Some graduate school & $6 \%$ \\
\hline Advanced degree & $16 \%$ \\
\hline Other (please specify) & $1 \%$ \\
\hline Total & $100 \%$ \\
\hline \multicolumn{2}{|l|}{ Annual Household Income Category } \\
\hline Less than $\$ 29,999$ & $14 \%$ \\
\hline$\$ 30,000-\$ 49,999$ & $23 \%$ \\
\hline$\$ 50,000$ to $\$ 74,999$ & $22 \%$ \\
\hline$\$ 75,000-\$ 99,999$ & $15 \%$ \\
\hline$\$ 100,000-\$ 129,999$ & $13 \%$ \\
\hline More than $\$ 130,000$ & $14 \%$ \\
\hline Total & $100 \%$ \\
\hline \multicolumn{2}{|l|}{ Current Employment Status } \\
\hline Working full time (includes self-employment) & $69 \%$ \\
\hline Working part time (includes self-employment) & $12 \%$ \\
\hline Unemployed & $7 \%$ \\
\hline Stay-at-home parent & $9 \%$ \\
\hline Retired & $2 \%$ \\
\hline Other (please specify) & $1 \%$ \\
\hline Total & $100 \%$ \\
\hline
\end{tabular}

\section{RESULTS}

Measuring Gratifications from Using LinkedIn

Exploratory factor analysis (EFA) for the 33 items in the LinkedIn gratification scale found three gratification factors from using the site. These three factors with eigenvalues of 1.0 or greater accounted for $67 \%$ of total variance. Communalities for all variables were greater than .50, indicating that the variables met acceptable levels of explanation (Hair, Black, Babin, et al., 2010, pp. 105). The Kaiser-Meyer-Olkin measure of sampling adequacy was .975, meeting acceptable levels (Hair et al., 2010, pp. 661).

Factor 1: Jobs and Job Affairs. Factor 1 contained four measures and an eigenvalue of 19.23 , accounting for $58 \%$ of variance. Chronbach's alpha was .929. LinkedIn customers obtain information about the professional world and search for jobs and are able to track these topics through the site; most of LinkedIn's features are designed to provide these benefits.

Factor 2: Social Aspects of Employment. Factor 2 included four measures, had an eigenvalue of 1.83, and accounted for $6 \%$ of variance. Chronbach's alpha was .824 . LinkedIn customers are gratified by the social aspects of employment. They want to see how others are portraying themselves, and they are curious about how they may appear. While they are searching for jobs, they are sensitive to their online presence. 
Factor 3: Finding Old and New Friends Easily. Factor 3 included four measures, had an eigenvalue of 1.1, and accounted for 3\% of variance. Chronbach's alpha was .833 . Customers may find these current and past connections based on suggestions of people they know, by using the search feature, and by visiting an alumni page associated with an employer or college. A listing of the items in each factor and factor loadings can be seen in Table 4.

Table 4. Items in Gratification Factors

\begin{tabular}{llc}
\hline Factor Title & Item & Factor Loading \\
\hline Jobs and Job Affairs & Finding out job opportunities & .861 \\
& Jobs you may be interested in & .855 \\
& Following the career progression of my contacts & .815 \\
Social Aspects of Employment & Viewing job ads posted by companies & .710 \\
& Searching for jobs & .706 \\
& Online presence & .698 \\
& Seeing who's viewed my profile & .662 \\
Finding Old and New Friends Easily & Viewing resumes of others & .592 \\
& User-friendly search engine & .730 \\
& Finding friends, alumni, etc. & .691 \\
& Ease of use & .667 \\
& Suggestion of people you know & .664 \\
\hline
\end{tabular}

\section{Measurement Model}

Structural equation modeling (SEM) was then used to test these constructs in a full measurement model, utilizing confirmatory factor analysis. Results for every item were found to be non-normal, so the robust method was used because it has been shown to correct for non-normality in large samples and perform better than uncorrected statistics where the assumption of normality fails to hold (Byrne, 2006). The key robust statistic for use with this non-normal data was the Satorra-Bentler scaled chi square (S-B scaled $X^{2}$ ).

Goodness of fit was acceptable: S-B scaled X2 $(176, \mathrm{~N}=390)=313.8983, p<0.01$; $\mathrm{BBNFI}=0.921 ; \mathrm{CFI}=0.963 ; \mathrm{RMSEA}=0.045(0.037,0.053)$. Values of 0.95 or higher are recommended for BBNFI and CFI, although values greater than 0.90 may be acceptable (Byrne, 2006). The CFI value of .963 meets the recommended standard, while the BBNFI value of .921 falls into the acceptable range. The RMSEA value of .045 indicates good fit. All Z-statistics were also greater than \pm 1.96 at the .05 level, suggesting that the estimate was statistically different from zero (Hair et al., 2010). Parameter estimates for the final measurement model are depicted in Table 5. 


\begin{tabular}{cccccc}
$\begin{array}{c}\text { Table 5. Measurement Model: Parameter Estimates } \\
\text { Variable } \\
\text { Number }\end{array}$ & Factor & Estimate & $\begin{array}{c}\text { Standard } \\
\text { Error (Robust) }\end{array}$ & $\begin{array}{c}\text { Z-Statistic } \\
\text { (Robust) }\end{array}$ & $\begin{array}{c}\text { Standardized } \\
\text { Estimate }\end{array}$ \\
\hline V1 & 1 & 1.000 & - & - & .874 \\
V2 & 1 & .948 & .053 & 17.95 & .739 \\
V3 & 1 & .869 & .059 & 14.62 & .676 \\
V4 & 1 & 1.022 & .042 & 24.16 & .883 \\
V5 & 2 & 1.000 & - & - & .804 \\
V6 & 2 & .941 & .053 & 17.68 & .792 \\
V7 & 2 & .844 & .054 & 15.61 & .682 \\
V8 & 2 & .881 & .059 & 14.85 & .663 \\
V9 & 3 & 1.00 & - & - & .795 \\
V10 & 3 & .853 & .060 & 14.27 & .704 \\
V11 & .772 & .055 & 14.02 & .719 \\
V12 & 3 & .913 & - & 17.14 & .763 \\
V13 & 3 & 1.000 & .052 & - & .767 \\
V14 & 4 & .710 & .045 & 13.74 & .721 \\
V15 & 4 & 1.110 & .060 & 24.45 & .815 \\
V16 & 4 & .985 & .056 & 16.42 & .708 \\
V17 & 4 & .944 & - & 16.73 & .811 \\
V18 & 4 & .877 & .099 & 14.09 & .747 \\
V19 & 4 & 1.000 & .090 & - & .919 \\
V20 & 5 & .676 & & 7.84 & .490 \\
V21 & 5 & .694 & & .541 \\
\hline
\end{tabular}

\section{Structural Model}

The structural model was then estimated using SEM. Three rounds of testing suggested that F1 (Jobs and Job Affairs) was influencing F2 (Social Aspects of Employment), and that F2 was influencing F3 (Finding Old and New Friends Easily), with $x^{2}$ reductions resulting from adding these parameters to the model. Jobs and Job Affairs (F1) was the strongest of the three gratifications, accounting for $58 \%$ of variance, and may drive the other gratifications.

In addition, LinkedIn usage (F5) was influencing intensity of attitudes (F4), with a $\mathrm{X}^{2}$ reduction resulting when this parameter was added to the model. No relationship was originally hypothesized between attitudes and usage, but results indicated that usage may influence attitudes toward the site. Customers who use the site more often and for greater periods of time may develop stronger attitudes because of those longer hours of exposure.

Goodness of fit. Goodness-of-fit measures met acceptable standards (Byrne, 2006): S$\mathrm{B}$ scaled $\mathrm{X}^{2}(177, \mathrm{~N}=390)=319.3575, p<.01$; BBNFI $=0.92 ; \mathrm{CFI}=0.962 ; \mathrm{RMSEA}=$ 0.045 (0.037, 0.053). Parameter estimates for this structural model are depicted in Table 6. 
Online Journal of Communication and Media Technologies, 2018

Table 6. Structural Model: Parameter Estimates

\begin{tabular}{|c|c|c|c|c|c|}
\hline Independent Factor & Dependent Factor & Estimate & $\begin{array}{c}\text { Standard Error } \\
\text { (Robust) }\end{array}$ & $\begin{array}{c}\text { Z-Statistic } \\
\text { (Robust) }\end{array}$ & $\begin{array}{l}\text { Standardized } \\
\text { Estimate }\end{array}$ \\
\hline Jobs and Job Affairs & $\begin{array}{l}\text { Social Aspects of } \\
\text { Employment }\end{array}$ & .847 & .048 & 17.53 & .861 \\
\hline $\begin{array}{l}\text { Social Aspects of } \\
\text { Employment }\end{array}$ & $\begin{array}{l}\text { Finding Old and New } \\
\text { Friends Easily }\end{array}$ & .834 & .064 & 12.94 & .838 \\
\hline Jobs and Job Affairs & $\begin{array}{l}\text { Intensity of LinkedIn } \\
\text { Attitudes }\end{array}$ & .051 & .072 & .710 & .076 \\
\hline $\begin{array}{l}\text { Social Aspects of } \\
\text { Employment }\end{array}$ & $\begin{array}{l}\text { Intensity of LinkedIn } \\
\text { Attitudes }\end{array}$ & .260 & .111 & 2.34 & .381 \\
\hline $\begin{array}{l}\text { Finding Old and New } \\
\text { Friends Easily }\end{array}$ & $\begin{array}{l}\text { Intensity of LinkedIn } \\
\text { Attitudes }\end{array}$ & .109 & .066 & 1.66 & .159 \\
\hline LinkedIn Usage & $\begin{array}{l}\text { Intensity of LinkedIn } \\
\text { Attitudes }\end{array}$ & .354 & .068 & 5.21 & .413 \\
\hline Jobs and Job Affairs & LinkedIn Usage & -.028 & .113 & -.247 & -.036 \\
\hline $\begin{array}{l}\text { Social Aspects of } \\
\text { Employment }\end{array}$ & LinkedIn Usage & .493 & .183 & 2.70 & .619 \\
\hline $\begin{array}{l}\text { Finding Old and New } \\
\text { Friends Easily }\end{array}$ & LinkedIn Usage & -.118 & .130 & -.904 & -.147 \\
\hline
\end{tabular}

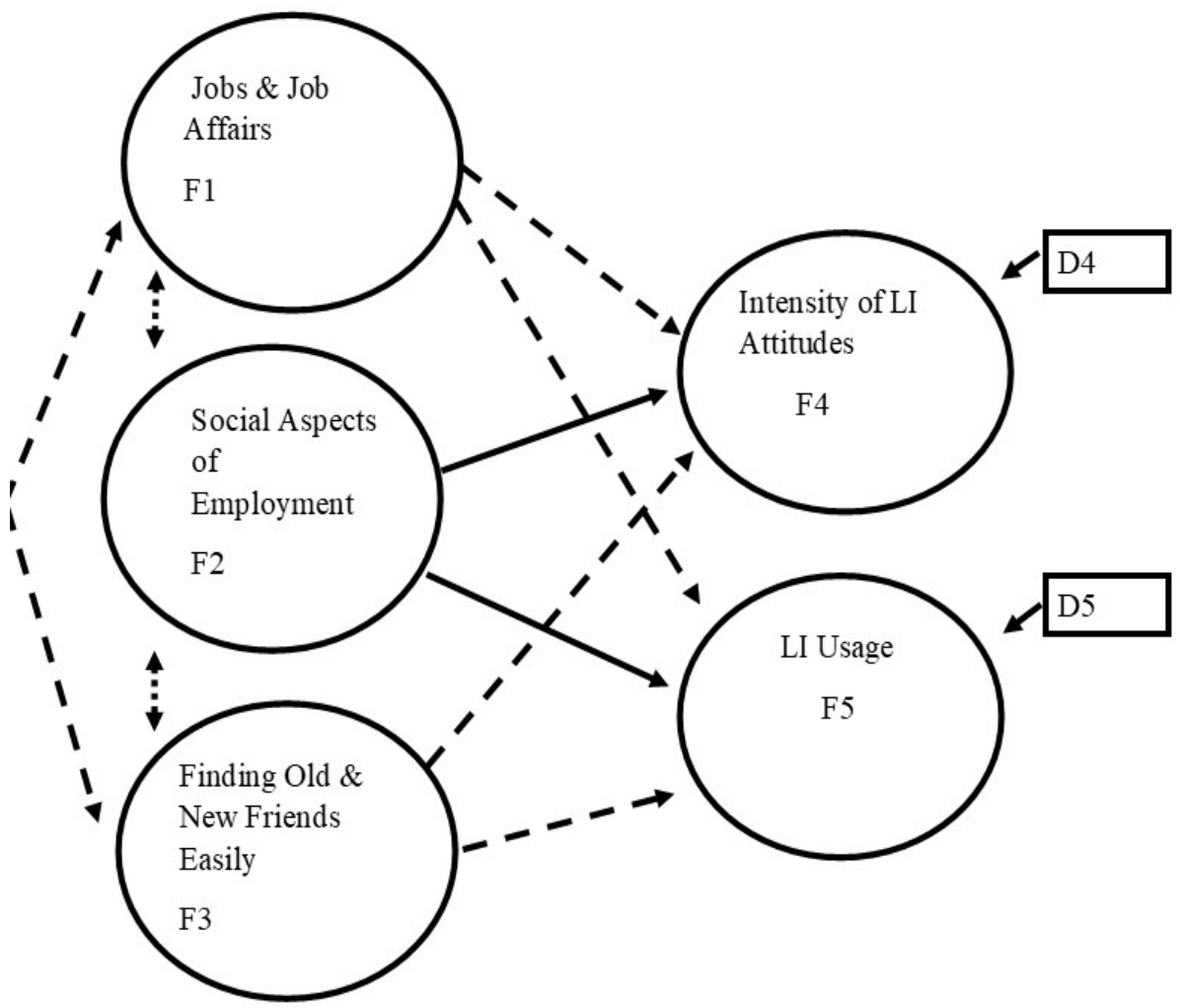

Figure 2. Final Structural Model

\section{Results of Hypothesized Relationships}

This research found support for $\mathrm{H} 3$ and $\mathrm{H} 4$, with significant positive relationships emerging between Social Aspects of Employment (F2) and both Intensity of LinkedIn Attitudes (F4) and LinkedIn Usage (F5). Support was not found for the other six hypotheses. The final structural model is depicted in Figure 2.

H3: Social Aspects of Employment -> Intensity of LinkedIn Attitudes. The relationship between the Social Aspects of Employment gratification (F2) and Intensity of LinkedIn Attitudes (F4) was hypothesized to be positive. Customers who are concerned with how they appear to their connections are using the site in part for image building or 


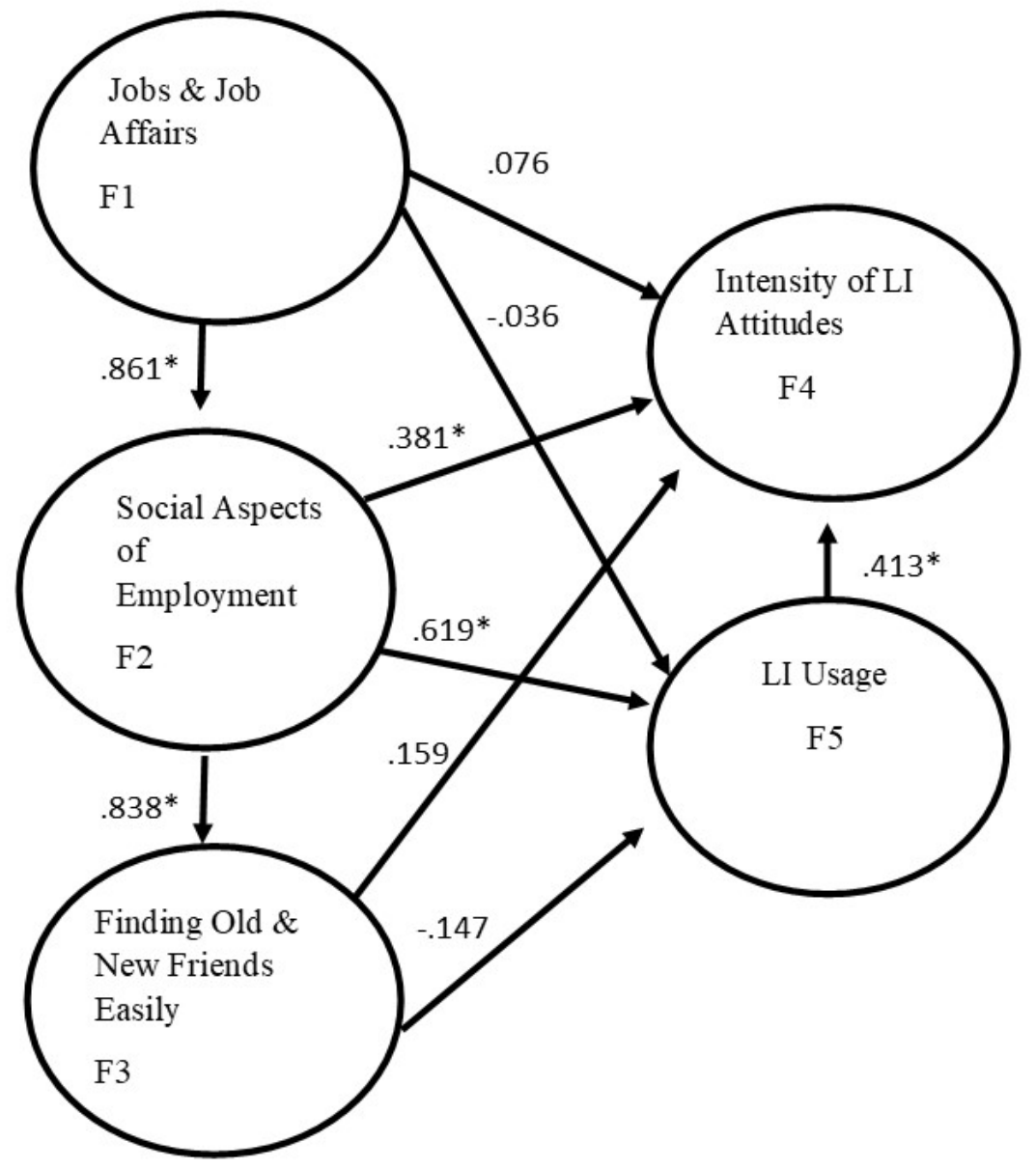

Figure 3. Structural Paths Between Factors

maintenance purposes and can be expected to have stronger attitudes about the site than those using it for other benefits. This positive relationship was found, with a Z-statistic of 2.34 and standardized estimate of .381.

H4: Social Aspects of Employment -> LinkedIn Usage. The relationship between Social Aspects of Employment (F2) and LinkedIn Usage (F5) was hypothesized to be positive, because those using the site for social reasons will use the site more often. This was confirmed with a Z-statistic of 2.70 and standardized estimate of .619.

\section{Post-Hoc Analysis}

While only two of the original eight hypotheses were supported, several significant results were found that were not part of the hypothesized research model. Variable 21 (Length of time for average site visit) was found to contribute to the Intensity of LinkedIn Attitudes factor (F4), while it was initially hypothesized to contribute only to LinkedIn Usage (F5).

Jobs and Job Affairs (F1) was found to contribute to Social Aspects of Employment (F2), and Social Aspects of Employment (F2) was found to contribute to Finding Old and New Friends Easily (F3). A positive dependence relationship was found between F4 and F5, with LinkedIn Usage (F5) contributing to Intensity of LinkedIn Attitudes (F4). Figure 3 depicts structural paths between factors, with asterisks indicating significant paths. 


\section{DISCUSSION}

Gratifications from Using LinkedIn

This study identified three gratifications from using LinkedIn: Jobs and Job Affairs, Social Aspects of Employment, and Finding Old and New Friends Easily. The first and third gratifications were also found in Basak and Calisir's 2014 study and are the benefits most associated with LinkedIn. The second gratification of Social Aspects of Employment represented a surprising finding. Respondents may be concerned with how they appear to others because this could affect career prospects, but a hedonic motivation may also be present; customers may find it interesting and even entertaining to monitor the career progression of their connections.

\section{Dependence Relationships between Gratifications}

The theme of $\mathrm{H}_{7}$ was that the gratifications from using LinkedIn would be interrelated, with no dependence relationships. However, significant dependence relationships were found between the three gratifications. F1 (Jobs and Job Affairs) contributed to F2 (Social Aspects of Employment), while F2 contributed to F3 (Finding Old and New Friends Easily). F1 was the strongest gratification emerging from factor analysis, accounting for a majority of variance, and may be driving the other two factors. A desire to learn about jobs could contribute to a concern for projecting the right image, which may then contribute to the desire to find other people.

\section{Role of Social Aspects of Employment}

Significant positive relationships were found between the Social Aspects of Employment factor and both intensity of attitudes regarding LinkedIn and LinkedIn site usage, showing that customers may be motivated by hedonic gratifications that are related to customer feelings about the site and its community of users, with those concerned about the social aspects reporting stronger attitudes toward LinkedIn and greater site usage.

\section{Relationship between Usage and Attitudes}

A significant positive relationship was found between the two endogenous variables, with F5 (LinkedIn Usage) contributing to F4 (Intensity of LinkedIn Attitudes), indicating that more time spent at the site is driving stronger attitudes. Customers may use LinkedIn to search for a job or because they derive pleasure from staying in touch, and the longer time spent in those pursuits leads to more intense attitudes toward the site and its community of users.

\section{Relevance to Earlier Research}

Similarities exist with earlier LinkedIn research; gratifications of learning information and monitoring others can be seen across studies, while the Social Aspects of Employment gratification does not have an equivalent in the other research. Common themes from Facebook studies have included keeping in touch, feeling connected to others, entertainment, passing time, following group norms, and social surveillance. Some of these gratifications are also received from LinkedIn, such as keeping in touch and feeling connected, while others are likely unique to personal SNSs, such as entertainment and passing time.

\section{Limitations}

Translation Issues. The measures in the LinkedIn Gratification scale were originally written in Turkish, and then translated into English by the authors (Basak \& Calisir, 2014). Some translation issues may have occurred during this process, which could have impacted the outcome of factor analysis. 
Self-Reporting. Sample members may have over- or under-represented their LinkedIn usage or mis-remembered their behavior. Respondents were asked to sign into their account and look at the number of connections and length of membership before starting the questionnaire, but there is no guarantee that they did so.

Limited to Members of Online Panels. The sample included only respondents who had expressed a willingness to complete web surveys by joining an online panel. There were benefits to this approach, but it also eliminated anyone who was not a member of an online panel, limiting the generalizability of findings to the broader audience of all LinkedIn customers.

Suggestions for Additional Research

Social Aspects of Employment. The Social Aspects of Employment gratification may be considered surprising, since LinkedIn is typically associated only with utilitarian career considerations. More research on this topic could provide greater insight into whether there is a social, enjoyable aspect of professional networking.

Finding Jobs through LinkedIn. The first gratification from using LinkedIn was Jobs and Job Affairs, and the site is commonly associated with seeking work. However, few studies seem to have been published about the efficacy of LinkedIn as a job-finding tool. A new examination could compare LinkedIn to other sources of employment information, such as online job listings, employment recruiters, and word-of-mouth communication.

\section{CONCLUSION}

This study contributes to the body of knowledge on an important topic. Three gratifications were found from using LinkedIn, and the importance of the Social Aspects of Employment gratification in attitudes and usage was reported. This is one of the first studies of LinkedIn gratification to focus on adult U.S. customers 25 and older and can help scholars to build a better understanding of professional social networking. It can also assist marketing and employment managers to make better decisions about the best usage of this popular and potentially powerful tool.

\section{REFERENCES}

Alhabash, S., Park, H., Kononova, A., Chiang, Y. H., \& Wise, K. (2012). Exploring the motivations of Facebook use in Taiwan. Cyberpsychology, Behavior, and Social Networking, 15(6), 304-311. https://doi.org/1i0.1089/cyber.2011.0611

Basak, E., \& Calisir, F. (2014). Uses and gratifications of LinkedIn: An exploratory study. In Proceedings of the World Congress on Engineering (Vol. 2). London, UK: World Congress of Engineering. Retrieved from http://www.iaeng.org/publication/ WCE2014/WCE2014_pp1153-1156.pdf

Blank, G., \& Lutz, C. (2016, July). The social structuration of six major social media platforms in the United Kingdom: Facebook, LinkedIn, Twitter, Instagram, Google+ and Pinterest. In Proceedings of the 7th 2016 International Conference on Social Media \& Society (p. 8). ACM. https://doi.org/10.1145/2930971.2930979

Blank, G., \& Lutz, C. (2017). Representativeness of social media in Great Britain: Investigating Facebook, LinkedIn, Twitter, Pinterest, Google+, and Instagram. American Behavioral Scientist, 61(7), 741-756. https://doi.org/10.1177/ 0002764217717559 
Online Journal of Communication and Media Technologies, 2018

Bonds-Raacke, J., \& Raacke, J. (2010). MySpace and Facebook: Identifying dimensions of uses and gratifications for friend networking sites. Individual Differences Research, 8(1), 27-33. https://doi.org/10.1.1.453.8866

Breitbarth, W. (2015). 2015 LinkedIn user survey. Milwaukee, WI: Power Formula. Retrieved from http://www.powerformula.net

Byrne, B. M. (2006). Structural equation modeling with EQS: Basic concepts, applications, and programming (2nd ed.). New York, NY: Psychology Press. https://doi.org/10.1207/s15328007sem1302_7

Cheung, C. M., Chiu, P. Y., \& Lee, M. K. (2011). Online social networks: Why do students use Facebook? Computers in Human Behavior, 27(4), 1337-1343. https://doi.org/10.1016/j.chb.2010.07.028

Claybaugh, C. C., \& Haseman, W. D. (2013). Understanding professional connections in LinkedIn - a question of trust. Journal of Computer Information Systems, 54(1), 94105. Retrieved from http://www.tandfonline.com/doi/abs/10.1080/08874417.2013. 11645675 https://doi.org/10.1080/08874417.2013.11645675

DeKay, S. (2009). Are business-oriented social networking web sites useful resources for locating passive jobseekers? Results of a recent study. Business Communication Quarterly, (March), 101-104. https://doi.org/10.1177/1080569908330378

Dhaha, I. S., \& Igale, A. B. (2013). Facebook usage among Somali youth: A test of uses and gratifications approach. International Journal of Humanities and Social Science, 3(3), 299-313. Retrieved from https://s3.amazonaws.com/academia.edu.documents/ 33293260/facebook_usage.pdf?AWSAccessKeyId=AKIAIWOWYYGZ2Y53UL3A\&Ex pires $=1504306861 \&$ Signature $=$ hnSSswRlWRdEo5zppIcAgg\%2F2jZs\%3D\&responsecontentdisposition=inline $\% 3$ B\%20filename\%3DFacebook_Usage_among_Somali_Yo uth_A_Test.pdf

Edwards, C., Stoll, B., Faculak, N., \& Karman, S. (2015). Social presence on LinkedIn: Perceived credibility and interpersonal attractiveness based on user profile picture. Online Journal of Communication and Media Technologies, 5(4), 102-115. Retrieved from http://www.ojcmt.net/articles/54/545.pdf

Ellison, N. B., Steinfeld, C., \& Lampe, C. (2007). The benefits of Facebook "friends": Social capital and college students' use of online social network sites. Journal of Computer Mediated Communication, 12(4), 1143-1168. https://doi.org/10.1111/j.10836101.2007. 00367.x

Ezumah, B. (2013). College students' use of social media: Site preferences, uses and gratifications theory revisited. International Journal of Business and Social Science, 4(5), 27-34. Retrieved from http://www.ijbssnet.com/journals/Vol_4_No_5_May_2013/ 3.pdf

Florenthal, B. (2015). Applying uses and gratifications theory to students' LinkedIn usage. Young Consumers, 16(1), 17-35. https://doi.org/10.1108/YC-12-2013-00416

Fortier, A., \& Burkell, J. (2016). Display and control in online social spaces: Towards a typology of users. New Media \& Society, 1-17. https://doi.org/10.1177/ 1461444816675184

Global social networks by number of users. (2015, November). Statista. Retrieved from http://www.statista.com

Hair, J. F., Black, W. C., Babin, B. J., \& Anderson, R. E. (2010). Multivariate data analysis (Vol. 7). New York, NY: Pearson. https://doi.org/10.1016/j.jmva.2009.12.014 
Inks, S., Schetzsle, S., \& Ovila, R. (2012). Exploring the use of social networking tools in sales: Current perceptions and future expectations. Marketing Management Journal, 22(1), 1-16. Retrieved from http://www.mmaglobal.org/publications/MMJ/MMJIssues/2012-Spring/MMJ-2012-Spring-Vol22-Issue1-Complete.pdf\#page=8

Katz, E. J., \& Blumler, G. (1974). The uses of mass communication: Current perspectives on gratifications research. Beverly Hills, CA: Sage.

Kim, J. Y., Shim, J. P., \& Ahn, K. M. (2011). Social networking service: Motivation, pleasure, and behavioral intention to use. Journal of Computer Information Systems, 51(4), 92-101. Retrieved from http://www.tandfonline.com/doi/abs/10.1080/08874417. 2011.11645505

Lampe, C., Wohn, D. Y., Vitak, J., Ellison, N. B., \& Wash, R. (2011). Student use of Facebook for organizing collaborative classroom activities. International Journal of Computer-Supported Collaborate Learning, 6(3), 329-347. https://doi.org/10.1007/ s11412-011-9115-y

LinkedIn Corporation stock information. (2016, January 22). Yahoo Finance. Retrieved from http://finance.yahoo.com

Most famous social network sites worldwide as of April 2017, ranked by number of active users (in millions). (2017, April). Statista. Retrieved from https://www.statista.com

Papacharissi, Z. (2009). The virtual geographies of social networks: A comparative analysis of Facebook, LinkedIn and A Small World. New Media \& Society, 11(1-2), 199-220. https://doi.org/10.1177/1461444808099577

Papacharissi, Z., \& Mendelson, A. (2011). [Toward a new(er) sociability: Uses, gratifications and social capital on Facebook]. In S. Papathanassopoulos (Ed.), Media perspectives for the 21st century (pp. 212-230). New York, NY: Routledge. Retrieved from http://zizi.people.uic.edu/Site/Research_files/NewerSociabilityMediaPerspectiv es.pdf

Park, N., \& Lee, S. (2014). College students' motivations for Facebook use and psychological outcomes. Journal of Broadcasting \& Electronic Media, 58(4), 601-620. https://doi.org/10.1080/08838151.2014.966355

Peachy, K. (2013). The new boys' club: The effect of gender on LinkedIn profiles. Sociological Viewpoints, 29(1), 17-37. Retrieved from https://www.questia.com/lib rary/journal/1P3-3226121401/2012-student-paper-competition-winner-the-new-boys

Schultz, R., Schwepker, C., \& Good, D. (2012). An exploratory study of social media in business-to-business selling: Salesperson characteristics, activities and performance. Marketing Management Journal, 22(2), 76-89. Retrieved from http://www.mmaglobal .org/publications/MMJ/MMJ-Issues/2012-Fall/MMJ-2012-Fall-Vol22-Issue2-Schultz -Schwepker-Good-pp76-89.pdf

Shyron, M. Q. (2015). Gaining access to social capital: The effects of gratifications sought, personality, and self-efficacy on LinkedIn use and social capital (Master's thesis). Retrieved from http://pg.com.cuhk.edu.hk/pgp_nm/projects/2015/MAQianyunShyron .pdf

Urista, M., Dong, Q., \& Day, K. (2008). Explaining why young adults use MySpace and Facebook through uses and gratifications theory. Human Communication, 12(2), 215229. Retrieved from http://www.uab.edu/Communicationstudies/humancommunicati on/merge.pdf\#page $=98$ 
Vivekananthamoorthy, N., Naganathan, E. R., \& Rajkumar, R. (2016). Determinant factors on student empowerment and role of social media and eWOM communication: Multivariate analysis on LinkedIn usage. Indian Journal of Science and Technology, 9(25), 1-12. https://doi.org/10.17485/ijst/2016/v9i25/95318

Witzig, L., Spencer, J., \& Galvin, M. (2012). Organizations' use of LinkedIn: An analysis of nonprofits, large corporations and small businesses. Marketing Management Journal, 22(1), 113-121. Retrieved from http://www.mmaglobal.org/publications/ MMJ/MMJ-Issues/2012-Spring/MMJ-2012-Spring-Vol22-Issue1-Witzig-SpencerGalvin-pp113-121.pdf

Zhang, Y., \& Leung, L. (2015). A review of social networking service (SNS) research in communication journals from 2006 to 2011. New Media \& Society, 17(7), 1007-1024. https://doi.org/10.1177/1461444813520477

Zide, J., Elman, B., \& Shohani-Denning, C. (2014). LinkedIn and recruitment: How profiles differ across occupations. Employee Relations, 36(5), 583-604. https://doi.org/10.1108/ER-07-2013-0086

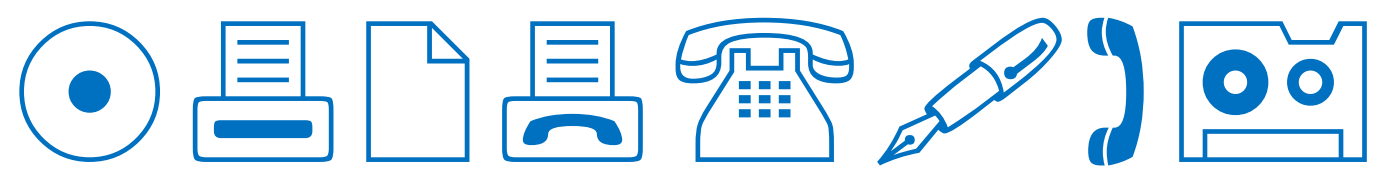

